\title{
Explicar um texto literário: o que a pesquisa em didática da literatura pode fazer para a renovação e a diversificação das práticas
}

Anne VIBERT ${ }^{1}$

Versão em português de Expliquer un texte littéraire: ce que la recherche en didactique de la littérature peut apporter au renouvellement et à la diversification des pratiques. 2012, feita por Helaine Giraldeli BALLA ${ }^{2}$

Se estamos todos de acordo sobre a necessidade de acabar com uma "concepção estreita da literatura, que a isola do mundo em que vivemos" (Todorov) e sobre dar sentido à leitura e ao estudo de textos literários, resta entretanto toda a questão do "como". Como, em particular, gerar interesse pela literatura?

O que eu gostaria de trazer aqui são algumas pistas propostas pelas pesquisas em didática da literatura, pois parece-me complicado fazer a economia de uma tal didática se queremos permitir a todo professor, e não somente a alguns mestres carismáticos, ensinar literatura.

Começarei por lembrar rapidamente as razões pelas quais emergiu, nos anos noventa, uma didática da literatura. Depois apresentarei uma visão geral de suas ancoragens teóricas e interesses, antes de abordar mais detidamente as proposições didáticas resultantes das pesquisas centradas na questão do sujeito leitor. As duas primeiras partes serão propositadamente curtas, pois destinam-se sobretudo a estabelecer os limites para a reflexão sobre o sujeito leitor que será desenvolvida de forma mais ampla.

\section{Da didática do francês à didática da literatura}

\section{A constituição de uma didática do francês e não de letras nos anos 70}

${ }^{1}$ Doutora em Língua e Literatura Francesa pela Universidade Stendhal, Inspetora Geral de Educaȩão. Nacionałda Universidade Estadual de Londrina. E-mail: hgiraldeliballa@gmail.com.

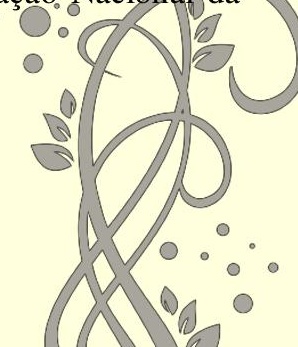


Revista Letras Raras

ISSN: 2317-2347 - Vol. 3, No 1 - 2014

França.

${ }^{2}$ Especialista em Literatura pela Unesp (Assis) e mestranda do Programa de Mestrado Profissional em Letras da

Universidade Estadual de Londrina. E-mail: hgiraldeliballa@gmail.com.

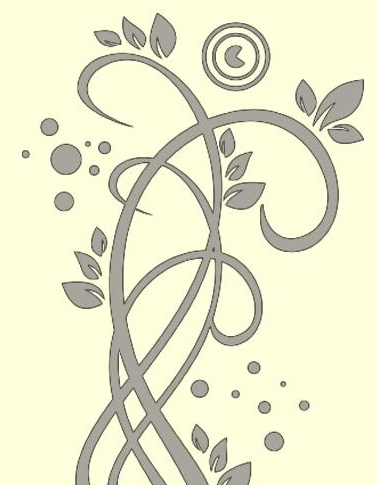


A didática do francês constituída nos anos 70 foi construída contra o ensino das letras, e particularmente contra o modelo tradicional desse ensino. Essa nova didática do francês esteve fortemente empenhada em contestar:

- Crítica à abordagem impressionista das obras, à racionalização dos seus sentidos, do julgamento estético e afetivo.

- Questionamento do papel da escola na reprodução das desigualdades sociais, em particular no campo da cultura literária.

- Influência da efervescência teórica dos anos 1950-60 (estruturalismo, new criticism, linguística da enunciação e pragmática) sobre a primeira geração de especialistas em didática, que encontraram aí uma legitimidade para criticar a velha ordem e as ferramentas teóricas e repensar o ensino da literatura.

Uma ênfase especial é dada à crítica dos livros didáticos em uso e às "peças escolhidas" (canonização dos textos literários), e mais ainda sobre a explicação do texto.

Sobre a influência das teorias estruturalistas e linguísticas, fortaleceu-se a ideia de uma leitura como puro "exercício de inteligência", como trabalho que não necessitasse nem de simpatia e nem de envolvimento emocional, mas de um saber fazer técnico e de um conhecimento científico: as análises objetivas poderiam então substituir a subjetividade cultural, a erudição literária, a comunicação estética. As instruções oficiais de 1987 introduziram então a leitura metódica no lugar da explicação do texto.

A didática apoiava-se nas noções do texto e do discurso (em substituição às de obras e de língua) e não havia uma determinação a priori de uma categoria de textos ditos literários suscetíveis a uma abordagem específica. $\mathrm{O}$ corpus de textos ampliou-se aos textos não literários (artigos de jornal, textos científicos, publicitários...) e menos espaço foi dado aos textos literários canônicos, eles foram integrados à grande categoria de "textos e documentos".

Nos anos 1980 houve o desenvolvimento de trabalhos sobre as tipologias textuais ou discursivas que fizeram ofuscar outras dimensões dos textos, notadamente as axiológicas e estéticas, em benefício do conhecimento de uma gramática textual.

Todos esses aspectos, por mais interessantes que sejam à contribuição para um melhor conhecimento do funcionamento linguístico dos textos, ajudaram a diminuir o espaço do litera

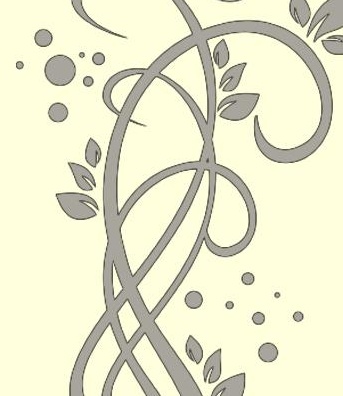


Revista Letras Raras

ISSN: 2317-2347 - Vol. 3, Nº - 2014

dentro da disciplina francês e fez suscitar uma "resposta literária" frente à dificuldade de se criar uma didática para a específica literatura.

Universidade Estadual de Londrina. E-mail: hgiraldeliballa@gmail.com.

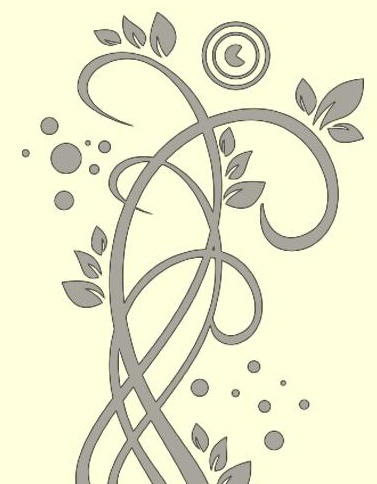




\section{A emergência do campo de pesquisa em didática da literatura nos anos 90}

Em um clima de interrogação no final dos anos 80 e início dos anos 90, a didática da literatura reivindica pouco a pouco sua especificidade, o que vai se traduzir em 2000 pela criação dos "encontros de pesquisadores em didática da literatura". Por que o desenvolvimento de uma pesquisa em didática da literatura nesse momento?

\section{a) As razões que afetam o ensino da literatura}

- uma resposta aos críticos sobre o formalismo dos estudos literários e sua deriva tecnicista: a leitura é reduzida a um levantamento, mais ou menos minucioso, de sinais "visíveis", frequentemente fenômenos sintáticos (tabelas de leitura), que ocupam os alunos com tarefas materiais objetivamente avaliáveis.

- um problema persistente: a desafeição pela literatura em geral e pela literatura em particular; a erosão literária (1960: 38,6\% de diplomados, 1992: 16,4 bacharéis); a crise persistente das humanidades e ao mesmo tempo a reafirmação de sua importância por meio de uma reflexão sobre os valores e finalidades da literatura.

\section{b) Uma renovação teórica}

No final dos anos 70 há uma ruptura epistemológica no campo dos estudos literários. Da primazia dada até agora ao texto e aos seus funcionamentos estruturais passamos à prioridade dada ao leitor e aos fenômenos de recepção. Diferentes trabalhos afirmam que a instância produtiva de sentido não é verdadeiramente ou não é somente o texto, mas sim e talvez em primeiro lugar seja o receptor, o sujeito que lê. Passamos então de uma concepção de literatura como coisa a uma literatura como atividade: a do escritor e a dos leitores, sem os quais o texto não tem existência.

\footnotetext{
${ }^{3}$ Institutos Universitários de Formação de Mestres. (N.T.).

${ }^{4}$ Didática do Francês/Língua Materna. (N.T.).
} 
Dessa forma, a didática da literatura vai se construir com base na atividade de leitura e nos encaminhamentos interpretativos.

${ }^{3}$ Institutos Universitários de Formação de Mestres. (N.T.).

${ }^{4}$ Didática do Francês/Língua Materna. (N.T.). 
professores e pesquisadores em didática da literatura, de dispor de um espaço específico de Vejamos a apresentação da revista Le Français Aujourd'hui, "Leitores de literatura", no

121, março de 1998, que testemunha esta situação:

Este número parece [...] oportuno em um contexto de questionamento vigoroso das derivas tecnicistas no ensino da literatura. [...] Embora a instrumentalização resultante das teorias (estruturalismo, linguística, narratologia) não tenha cumprido todas as suas promessas, ela pode ter agido como isca para resolver as dificuldades de acesso à literatura para um público que não funciona mais dentro da compreensão cultural - se é que este tenha sido o caso. Mas o risco seria grande de um retorno ao passado, ao impressionismo da explicação, ao brilho original que ocultaria o fato de que esse retorno às ferramentas teve ligação com a democratização do ensino.

[...] de uma era concentrada no encerramento do texto e seus mecanismos, parece que passamos a uma centração sobre o sujeito leitor e então sobre a recepção da literatura. O que implica revisar um bom número de representações e de práticas na sala de aula. Essa inclusão do leitor deve ainda se impor, mas sobre novas interrogações. Em especial, que mediações, que ferramentas utilizar ou inventar para acompanhar os alunos na apropriação de uma relação com os textos literários e, por conseguinte, à literatura? (p.3-4)

\section{c) As razões mais institucionais}

- os novos programas para o collège em 1996, para o lycée em 2001 e em seguida para a escola primária em 2002 que renovaram conteúdos e métodos de ensino da literatura e suscitaram reações, debates e novos objetos de pesquisa;

- a incitação ao desenvolvimento de pesquisa nos IUFM $^{3}$ e o desejo dos pesquisadores em literatura de não abandonar esta pesquisa aos especialistas em didática vindos das ciências da linguagem, muito ativos no campo da didática do francês, notadamente através da Associação Internacional para a Pesquisa em Didática do Francês (AIRDF) que sucedeu à DFLM $^{4}$.

\section{d) O que reivindicam os pesquisadores em didática da literatura?}


Revista Letras Raras ISSN: 2317-2347 - Vol. 4, No1 - 2014

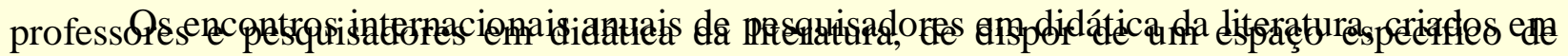
março de 2000, advêm da necessidade amplamente sentida dentro da comunidade dos 
intercâmbio. Estes pesquisadores desejam igualmente:

- distinguir-se da posição de recuo que constitui frequentemente a referência à literatura (mal-estar latente que inspira a alguns os comportamentos defensivos e conservadores).

- questionar as rupturas entre os diferentes níveis de ensino: pensar uma disciplina de ensino do maternal ao nível final (como já acontecia no caso da disciplina francês) - o que se distingue de alguns movimentos como o "Salvar as letras" que se interessam pela literatura somente no secundário.

- reafirmar a especificidade da literatura e sua importância no ensino e compensar a diminuição do literário na abordagem global do ensino do francês.

Esse projeto correspondia sem dúvida a uma real necessidade, uma vez que após 10 anos esses encontros acontecem, a cada ano, o que deu origem a um importante desenvolvimento da pesquisa em didática da literatura.

\section{A pesquisa em didática da literatura: os objetos específicos}

Em uma década constituiu-se um campo de pesquisa com seus objetos e seus métodos. Eu me deterei aqui somente nos que estão ligados ao nosso sujeito, a explicação literária.

\section{Uma reflexão sobre a leitura literária e o papel do sujeito leitor no ensino da literatura}

Baseando-se em particular nos trabalhos em sociologia da leitura, a didática da literatura examinou as relações entre a leitura privada e a leitura escolar. Não podemos ignorar o antigo conflito e tensão entre ambas, ainda que a instituição escolar tenha inventado novas formas de leitura inspiradas na leitura privada (leitura de obras integrais, leitura superficial) para suscitar o desejo de ler e reafirmar a leitura literária dentro da leitura habitual dos alunos. Porém, objetos e práticas passam com dificuldades de um espaço a outro e a didática da literatura não cessa de procurar dispositivos para tentar conciliar essas duas formas de leitura.

Portanto, é a noção de patrimônio literário ou cânone que está sendo questionada. 
Dar lugar à leitura subjetiva em sala de aula é uma das vias possíveis desta reconciliação.

Voltaremos

a

essa

questão

mais

adiante.

Portanto, é a noção de patrimônio literário ou cânone que está sendo questionada. 


\section{Uma redefinição das noções de interpretação e de compreensão}

Questionando a hierarquia tradicional, a progressão do compreender para depois interpretar e a visão da interpretação como prática reservada ao ensino secundário e à universidade, a didática da literatura tem trabalhado para aprofundar o conhecimento e a descrição dos atos de compreensão e de interpretação das obras literárias e artísticas: ela prevê a relação entre compreensão e interpretação em todos os níveis de ensino e considera que a compreensão e a interpretação estão em ação na leitura de todo texto. As experiências realizadas em sala de aula antes e após a publicação dos programas de 2002 para a escola primária testemunham amplamente essa ideia. Esses mesmos programas introduziram o debate interpretativo como atividade específica para abordar a literatura e convidaram os professores a praticá-lo desde o maternal.

\section{Uma reflexão sobre o corpus}

Outro objeto de estudo privilegiado pela didática da literatura: a reflexão sobre o corpus. O estudo da constituição do corpus levanta a questão da definição de literatura escolar e além dela, talvez, aquela definição de literatura tão curta, para retomar a célebre réplica de Barthes, "a literatura é o que se ensina". Ora, após os anos 60, esse corpus foi bastante abalado e expandido. A legitimação da literatura juvenil, por meio das listas que acompanhavam os programas do collège de 1996, e após pelos programas escolares de 2002, provocou não apenas numerosos debates, mas acima de tudo abriu um novo campo de pesquisa, tanto no âmbito dos estudos literários, quanto no de pesquisa em didática sobre a maneira de ensinar esta literatura na escola.

Antes disso, o corpus lido e estudado na escola tinha conhecido outras ampliações: do lado dos "gêneros menores", ficção científica e literatura policial; do lado das histórias em quadrinhos; do lado enfim das literaturas francófonas e das literaturas estrangeiras (exceto a literatura infantil) ou ainda da literatura contemporânea para adultos. Esta abertura a novos

Portanto, é a noção de patrimônio literário ou cânone que está sendo questionada. 
campos (sem ainda falar da imagem e do cinema) entra em tensão e em contradição com o objetivo de transmissão da herança cultural que também é atribuído ao ensino da literatura.

Portanto, é a noção de patrimônio literário ou cânone que está sendo questionada. 
Mas ainda é necessário conhecer as opções que são realmente feitas pelos professores, e se o estudo do corpus explícito (instruções oficiais, livros didáticos) é rica em conteúdo, principalmente numa perspectiva diacrônica, a pesquisa busca igualmente trazer à luz o corpus implícito, particularmente as escolhas dos professores, seus critérios, os valores subjacentes, os equilíbrios e os consensos sobre as obras destinadas à leitura e ao estudo.

Assim, uma pesquisa foi realizada em 2006 com uma amostra representativa de professores do collège para melhor conhecer o que os professores levam para os alunos lerem como obras integrais e como leitura superficial, o objetivo era medir as evoluções ocorridas após a pesquisa realizada no início dos anos 90. Para resumir em poucas palavras, pôde-se constatar entre os professores de francês:

- uma presença sempre muito forte dos clássicos ligada à ideia da transmissão do patrimônio cultural como uma das principais tarefas da sua disciplina;

- uma forte presença da literatura juvenil e a adesão às orientações dos programas de 1996;

- uma dispersão geral de títulos citados, o que comprova a instabilidade do corpus e a dificuldade de fazer emergir uma cultura comum que faria gerar um consenso;

Esses resultados demonstram compromisso e hesitação com relação aos valores:

Embora pareça que os professores tenham um papel a cumprir enquanto professores de literatura, sua concepção de literatura parece menos clara na prática do que seria se pensassem nas respostas às questões sobre o patrimônio literário mencionado acima. Como atestam seus julgamentos a respeito da literariedade das obras que lhes foram apresentadas em outra pergunta e as fortes variações, às vezes inexplicáveis, desses julgamentos em relação a 1994, como se o caráter mais ou menos acessível de uma obra para os alunos de hoje viesse a ser interpretado como um índice de literariedade. Além disso, o corpus de trabalho não é mais estável, sem dúvida ele é mais influenciado por alguns modos e sucesso do momento, pelos efeitos da oferta editorial ou por proposições de algumas revistas pedagógicas do que por certezas sobre o valor das obras. É difícil então fazer emergir uma cultura comum que construiria um consenso, cada um buscando o melhor acordo entre as prescrições personnel des enseignants à la littérature. In: DUFAYS, J-L. Enseigner et apprendre la littérature aujourdêhui, pourquoi faire? Sens, utilité, évaluation. Presses Universitaires de Louvain, 2007. 
dos programas, suas concepções e gostos pessoais e a realidade dos alunos. Os primeiros resultados da nossa pesquisa demonstram haver

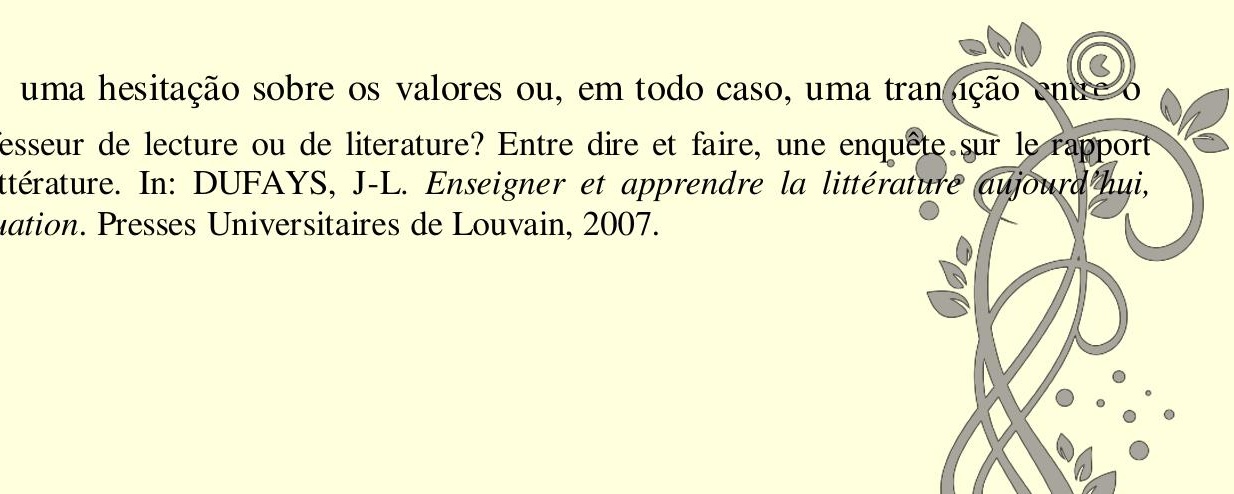

${ }^{5}$ OLIVIER, I., VIBERT, A. Professeur de lecture ou de literature? Entre dire et faire, une enquête.sur le rapport personnel des enseignants à la littérature. In: DUFAYS, J-L. Enseigner et apprendre la littérature aujourdhui, pourquoi faire? Sens, utilité, évaluation. Presses Universitaires de Louvain, 2007. 
modelo antigo, ainda bem representado pela pesquisa de 1994, e o novo que se busca. ${ }^{5}$

Enfim, uma reflexão mais recente sobre a biblioteca interior, relacionada à questão do sujeito leitor, aconteceu nos encontros de Bordeaux. As investigações centram-se na cultura literária construída pela escola: o que os alunos retêm do corpus, o que eles fazem e a maneira que constroem sua biblioteca interior a partir (ou não) das proposições dos professores. Essas pesquisas questionam o fosso entre a cultura institucionalmente proposta e a cultura literária interiorizada.

\section{As pesquisas sobre o sujeito leitor: pistas sugestivas para uma outra abordagem para a explicação literária?}

\section{A. Quadro geral das pesquisas sobre o sujeito leitor: a reflexão didática sobre a leitura literária}

A noção de "leitura literária" aparece "oficialmente" em 1984 quando Michel Picard a consagra num colóquio em Reims. Depois disso ela é retomada por educadores e no meio universitário, como fez Vicent Jouve, que lançou uma revista intitulada A leitura literária. O termo tem uma real importância no campo didático nos anos 90 e se permite apoiar nas mais recentes pesquisas literárias (as teorias da leitura dos anos 70) e nas inúmeras pesquisas didáticas sobre a aprendizagem da leitura (reflexões didáticas sobre a compreensão de inspiração psicolinguística, que renovaram a prática da leitura escolar). Essa noção propicia o questionamento do ato de leitura (notadamente a escolar) e a concepção de um ensino que não seja apenas centrado no texto, mas na relação texto-leitor.

\section{Origem: a importância das teorias sobre a leitura para os campos da leitura e da literatura no final dos anos 70 e início dos anos 80}

uma hesitação sobre os valores ou, em todo caso, uma tran 1ção ennễ

${ }^{5}$ OLIVIER, I., VIBERT, A. Professeur de lecture ou de literature? Entre dire et faire, une enquête.sur le rapport personnel des enseignants à la littérature. In: DUFAYS, J-L. Enseigner et apprendre la littérature aujourd hui, pourquoi faire? Sens, utilité, évaluation. Presses Universitaires de Louvain, 2007. 
a) Teorias agrupadas por comodidade sob a denominação de “teorias da recepção":

uma hesitação sobre os valores ou, em todo caso, uma tran ${ }^{5}$ OLIVIER, I., VIBERT, A. Professeur de lecture ou de literature? Entre dire et faire, une enquête.sur le rapport personnel des enseignants à la littérature. In: DUFAYS, J-L. Enseigner et apprendre la littérature aujourd'hui, pourquoi faire? Sens, utilité, évaluation. Presses Universitaires de Louvain, 2007. 
Abordagens:

- sócio-histórica de Hans Robert Jauss: Pour une esthétique de la réception (1972); Pour une herméneutique littéraire (1982),

- poética e estética de Wolfgant Iser: L'acte de lecture, théorie de l'effet esthétique (1976),

- ou semiótica de Umberto Eco: Lector in fabula, 1979.

\section{b) Abordagem psicanalitica de Michel Picard}

Em La lecture comme jeu (1986), M. Picard não se interessa pelo leitor abstrato, como Iser ou Eco, mas pelo leitor real, empírico, numa perspectiva psicanalítica. Foi ele o primeiro a utilizar o termo "leitura literária" e a examinar as consequências pedagógicas das proposições teóricas que elabora.

Em La lecture comme jeu, ele separa no interior da ato da leitura a existência de três instâncias leitoras no leitor, três identidades que se superpõem e interagem:

- o liseur (ledor) "secretamente mantido, por suas percepções, seu contato com a vida fisiológica, a presença preliminar mas constante do mundo exterior e de sua realidade". É o corpo que lê.

- o lu (lido) abandona-se aos "impulsos mais ou menos sublimados, às identificações, [...] do princípio do prazer", "até os limites da fantasia". Ele remete ao inconsciente do leitor que reage ao texto e deixa-se levar pelas emoções. É o leitor capturado pelo jogo, sujeito à ilusão referencial, à instância solicitada pelo "play", o investimento imaginário.

- o lectant (leitante) faz entrar no jogo por prazer a secundaridade, atenção, reflexão, trazendo um saber crítico. Trata-se da instância intelectual capaz de recuos para interpretar o texto, é o leitor crítico, consciente de que ele joga, aquele que coloca o texto à distância e se interessa pela complexidade da obra.

"Assim, todo leitor será tríplice (mesmo se um ou outro de seus componentes é atrofiado)". Durante a atividade de leitura essas três instâncias interferem em um jogo sutil de participação e de distanciamento, o liseur e o $l u$, fundamentam a participação e o investimento fantástico do sujeito leitor, e o lectant instaura uma distância com o texto. A leitura literária é 
Essa oscilação participação-distanciamento nutre o prazer do leitor. Definitivamente, segundo Michel Picard, é no entanto a postura distanciada que permite o prazer estético.

\section{c) modelo retomado e definido por Vincent Jouve 6 que:}

- renuncia ao liseur;

- retoma o lu como elemento passivo por se referir aos efeitos da leitura sobre o inconsciente do leitor e à satisfação de certos impulsos inconscientes. É o "nível de leitura onde, através de certas cenas, o leitor reencontra uma imagem de suas próprias fantasias".

- refina o lectant baseando-se na ideia de que o texto é essencialmente uma construção que supõe um arquiteto: o autor que guia o leitor na relação com o texto. Ele distingue:

- o lectant jouant que tenta adivinhar a estratégia narrativa do texto,

- o lectant interprétant que visa a decifrar o sentido global da obra;

- inventa o lisant, instância que se deixa prender pela ilusão referencial e aceita crer no mundo fictício temporal da leitura.

\section{Definição de leitura literária}

É preciso entender a leitura literária não somente como a leitura da literatura que compreende as diferentes formas escolares (explicação do texto, leitura metódica, leitura analítica), mas como uma concepção de leitura baseada na tensão entre leitura investida (leitura vivida intimamente numa identificação e/ou projeção do leitor nos espaços de fantasia que o texto propõe) e leitura distanciada, mais objetiva, apoiada em ferramentas de análise, para a elaboração de significações racionais.

Se, como sugerem os semióticos e teóricos da recepção, a obra literária deve ser sempre atualizada e completada graças ao investimento de seus leitores, este não será limitado a uma atitude racional e treinada. Quando se interessa pelo texto que lê, o leitor não adota somente a "postura letrada" que é aquela construída pelo ensino da literatura através dos exercícios clássicos (comentário feito a partir da obra): ele se envolve com a obra. Veremos adiante de@ue forma. 
${ }^{6}$ Em L'Effet personnage dans le roman (1992). Ver também do mesmo ator A Leitura, Unesp, 2002. 


\section{Questões que envolvem a leitura literária concebida como vai-e-vem dialético entre leitura subjetiva, investida e leitura distanciada}

Trata-se, recorrendo a tal concepção de leitura literária, de responder a uma crise da leitura literária e de defender o ensino de letras no contexto difícil de desafeição do público adolescente pela leitura literária (confirmada por trabalhos dos sociólogos da leitura). Essa concepção é também uma resposta às críticas feitas à leitura metódica e analítica.

Dar lugar ao sujeito leitor na leitura literária é um meio de restaurar o sentido, pessoal e social, a um ensinamento literário muito marcado pelo formalismo e pelo tecnicismo. As críticas convergem para pontuar a ausência de investimento subjetivo, intelectual e emotivo dos alunos dentro do que se constituiu como um ritual de exercício (uma prática sem crença, para lembrar a expressão de Christian Baudelot).

Pouco surpreendente: a leitura analítica pretende formar um leitor hábil em responder às injunções do texto e este leitor enquanto sujeito não tem voz. Ensinar literatura é, de uma certa maneira, codificar a maneira de ler as obras, como nos lembra Alain Viala. De repente, e com frequência, o aluno se desengaja e não se afirma face ao texto. De fato, os alunos se veem incapazes de formular um julgamento crítico sobre o texto, paralisados pelo medo de não dizer o que é esperado pelo professor.

Mas isso ainda não é tudo, veremos mais adiante o retorno do pêndulo que é considerar o texto literário como um simples suporte da efusão subjetiva.

\section{B. A questão do sujeito leitor}

A problemática do sujeito leitor se inscreve na teoria geral da leitura literária como interação entre leitores e obras. Em 2004, a noção de sujeito leitor foi abertamente questionada

\footnotetext{
${ }^{7}$ Qui a tué Roger Ackoyd? 1998, p.127.

${ }^{8}$ Ibid. p. 130.

9 LACELLE,N.; LANGLADE, G. Former des lecteurs/spectateurs par la lecture subjective des oeuvres. In : DUFAYS, J-L, Enseigner et apprendre la littérature aujourd'hui : pourquoi faire? P.U. Louvain, 2007.
} 
no colóquio de didática em Rennes. Em 2007, a revista Le français aujourd'hui consagra-lhe um número: "Sujeito leitor, sujeito escritor, questões para o ensino?" (n 157, junho de 2007).

A questão da subjetividade do leitor foi abordada de maneira teórica dentro da reflexão crítica sobre a literatura: tratava-se de estudar as estratégias acionadas pelos leitores para dar vida às obras e às reconfigurações das obras pela atividade dos leitores. A reflexão didática ficou

${ }^{7}$ Qui a tué Roger Ackoyd? 1998, p.127.

${ }^{8}$ Ibid. p. 130.

9 LACELLE,N.; LANGLADE, G. Former des lecteurs/spectateurs par la lecture subjective des oeuvres. In : DUFAYS, J-L, Enseigner et apprendre la littérature aujourd'hui : pourquoi faire ?. P.U. Louvain, 2007. 


\section{O envolvimento do leitor com a obra: uma necessidade funcional da leitura literária}

Como escreve Pierre Bayard, "o mundo que produz o texto literário é um mundo incompleto [...] onde partes inteiras da realidade faltam" $\mathrm{e}^{\text {"o }}$ texto se constitui por uma parte significativa de reações individuais de todos os que o encontram e lhe dão vida com sua presença"8.

Assim, a partir de falhas ficcionais, ou detalhes minúsculos, partes inteiras da vida de um personagem podem ser "completadas". A reflexão teórica então tem mostrado que uma parte da leitura investida existe nos leitores experts, eruditos, particularmente nos grandes leitores que são os escritores (Balzac, leitor de La Chartreuse de Parme, Journal de Gide, Journées de lecture de Proust, Journal de lectures de Alberto Manguel, P. Dumayet, Autobiographie d'un lecteur...) $\mathrm{O}$ leitor, não importa quem ele seja, realiza um investimento ficcional na obra ao afirmar a coerência "objetiva" de sua leitura.

O conteúdo ficcional de uma obra sempre é investido, transformado, singularizado, pela atividade ficcionalizante do leitor que produz as imagens e os sons completando a obra (concretização imagética e auditiva) reage às características formais (impacto estético), estabelece elos de causalidade entre os acontecimentos e as ações dos personagens (coerência mimética), recenariza os elementos de intriga a partir de seu próprio imaginário (atividade de fantasia), tem julgamentos sobre a ação e a motivação dos personagens (reação axiológica). ${ }^{9}$

\section{Uma reflexão que teve de se firmar em um contexto desfavorável}

De fato, a leitura de envolvimento é considerada a priori como de menor valor: tradicionalmente, ela é remetida aos leitores crédulos, imediatos, isto é, infantis, populares, não eruditos... A escola empenhou-se em refrear toda tentativa de envolvimento afetivo dos alunos para levá-los a uma leitura distanciada, a leitura do expert e do letrado. Trata-se de uma

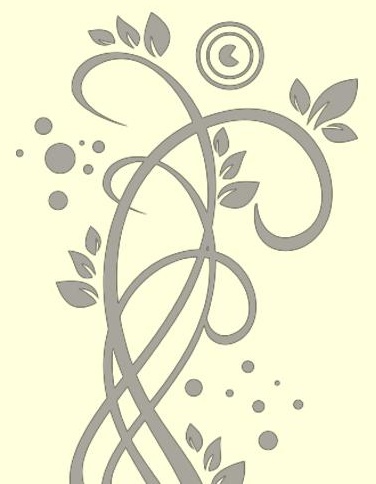


tendência de longa duração porque, já para Lanson, importava antes de tudo escapar aos caprichos do leitor alcançando "um conhecimento impessoal verificável" das obras.

Apoiando-se em diferentes trabalhos, J-F. Massol e B. Milcent colocaram em evidência, no colóquio sobre "O texto do leitor" (Toulouse, 2008), as relações, frequentemente de oposição, que existem entre a postura letrada exigida pelo comentário atual e a subjetividade leitora:

Assim podemos opor:

1. a "concretização imagética e auditiva" versus a desconfiança da leitura letrada para os acréscimos pessoais;

2. as recomposições às quais procede o sujeito leitor versus o respeito aos "direitos do texto" em que a descoberta é guiada pelo leitor modelo;

3. a "reação axiológica"que leva o leitor aos julgamentos sobre as ações e a motivação dos personagens versus o hábito recente da objetividade do olhar sobre o texto, que não deixa se interessar pelos personagens como pessoas;

4. a "coerência mimética" que estabelece elos de causalidade entre os acontecimentos e ações dos personagens versus uma concepção de obra considerada dentro de uma integralidade que supõe imediatamente uma plena coerência.

A atividade do leitor conduz a uma reconfiguração da obra lida e ao que Pierre Bayard nomeou de "texto singular do leitor".

Podemos colocar o texto do leitor no centro da didática de leitura literária? Uma didática de envolvimento do leitor é possível na sala de aula?

\section{Abordagens didáticas}

Antes de falar das práticas estreitamente relacionadas à explicação literária, abordarei rapidamente as autobiografias do leitor, que são uma etapa possível na construção do sujeito leitor na medida em que elas permitem que alguém se conheça como um leitor.

\footnotetext{
${ }^{10}$ ROUXEL, A. Autobiographies de lecteur et identité littéraire. In : ROUXEL, A.; LANGLADE, G. (dir.). Le sujet lecteur, lecture subjective et enseignement de la littérature. PUR, 2004.
} 
1. As autobiografias do leitor: conhecer-se como leitor para a construção do sujeito leitor a) Práticas com os alunos

${ }^{10}$ ROUXEL, A. Autobiographies de lecteur et identité littéraire. In : ROUXEL, A.; LANGLADE, G. (dir.). Le sujet lecteur, lecture subjective et enseignement de la littérature. PUR, 2004. 
As autobiografias de leitor foram experimentadas por Annie Rouxel com alunos do lycée. Apesar das dificuldades (como assumir um status de não leitor? falar da sua falta de interesse e de seu tédio? da obrigação das leituras literárias?) a prática é rica em ensinamentos para os sujeitos leitores em formação: "Fazendo advir à consciência uma imagem de si mesmo, a biografia constitui frequentemente o gesto fundador de uma identidade de leitor que está se formando ou se firmando"10. Ela permite também aos professores descobrir como se constrói a relação com a leitura e com a literatura.

As biografias do leitor foram também experimentadas por J-L. Dufays e Severine De Croix com alunos mais jovens num dispositivo mais complexo que visava desenvolver a consciência metacognitiva melhorando a percepção de si mesmo como sujeito leitor.

Quadro experimental: duas produções são solicitadas em sala de aula:

$1^{\mathrm{a}}$ - Um relato de leitor/leitora: que leitor eu penso ser hoje apoiando-me em minhas últimas leituras?

$2^{\mathrm{a}}$ - Uma autobiografia de leitor com algumas restrições: respeito à cronologia dos acontecimentos, esforço de memória para ir o mais longe possível no passado antes de voltar ao dia de hoje.

Entre as duas, diversas atividades em torno de cenas de leitura advindas da literatura para serem trabalhadas com os adolescentes.

Questões:

1. para os professores: ter acesso às representações iniciais dos alunos com relação à leitura: eles consideram que a leitura de um conto por um dos pais é uma forma de leitura? Podemos nos considerar leitores assíduos se lemos apenas revistas? histórias em quadrinhos?

2. para os alunos: entrar em uma marcha reflexiva sobre si mesmo: pesquisa na memória, interrogações sobre os gostos, escolhas, hábitos e atitudes. Expressão dos prazeres e desprazeres. Análise das causas e explicações. 
Revista Letras Raras ISSN: 2317-2347 - Vol. 4, No1 - 2014

Colocar em evidência os perfis de leitores e traços metacognitivos na produção final. Analisar os resultados que parecem corroborar a hipótese segundo a qual um indivíduo se 
desenvolve enquanto sujeito à medida que pratica um olhar reflexivo e à medida que se sente valorizado em suas práticas culturais.

Para contornar a dificuldade que representa a escrita para alguns alunos, podemos também provocar neles uma reflexão sobre si mesmos como leitores pedindo que se representem lendo por meio de desenho ou outra forma de representação plástica.

\section{b) Práticas com os professores em formação}

Essa atividade de tomada de consciência é mais interessante ainda com os futuros professores, pois o sujeito leitor não é apenas o aluno ou o estudante: é também o professor. Antes de suscitar nos alunos as experiências pessoais de leitura, é desejável que um futuro professor se conheça como leitor. Para engajar os professores em formação ou os estudantes que se preparam para o métier do ensino a uma marcha reflexiva, podemos solicitar a escrita de sua biografia de leitor.

Esta atividade foi experimentada por Dominique Ledur e Séverine De Croix, na Bélgica. Eu mesma já fiz a experiência com professores estagiários. A atividade permite aos jovens professores retraçar seu itinerário de leitor partindo do que se foi (ou crê ter sido) para se questionar sobre o que se é hoje e assim esboçar a grandes traços seu autorretrato de leitor. $\mathrm{O}$ retorno a si abre-se naturalmente a uma projeção de si em seu papel futuro de "mestre de leitura".

A experiência permite o início de uma mudança, a descoberta de posturas de leitura diferentes em um mesmo leitor e a tomada de consciência de eventuais discordâncias entre seus gostos e suas práticas reais de leitor e o que supomos que se deve demonstrar ou ensinar. Ela permite ainda colocar em evidência o que Bernard Lahire demonstrou com a pesquisa sobre $L a$ culture des individus, dissonnances culturelles et distinction de soi (La Découverte, 2004), ou seja, um mesmo indivíduo pode ter práticas culturais de diferentes níveis de legitimidade. Sem negar os resultados das desigualdades sociais frente à cultura legitimada e apagar o quadro de realidade cultural pintado por quarenta anos de trabalho sobre os usos sociais da cultura, Bernard Lahire analisa os fenômenos de dissonâncias culturais no interior dos grupos sociais e nos

\footnotetext{
${ }^{11}$ La question du sujet lecteur en didactique de la lecture littéraire. In: FALARDEAU, E. et al.(dir.) La didactique du français: les voies actuelles de la recherche. Québec, PUL, 2007.
} 
indivíduos eles mesmos. No que concerne aos jovens professores, suas biografias de leitor demonstram que há, às vezes, pouca distância entre as suas práticas culturais e as dos seus alunos.

${ }^{11}$ La question du sujet lecteur en didactique de la lecture littéraire. In: FALARDEAU, E. et al.(dir.) La didactique du français: les voies actuelles de la recherche. Québec, PUL, 2007. 


\section{Considerar o sujeito leitor: condição de motivação dos alunos}

Um certo número de pesquisas já demonstrou que o conhecimento do investimento subjetivo na leitura é condição importante para a motivação dos alunos sob a perspectiva de uma construção de competências de um leitor expert, uma das finalidades dos estudos do francês no collège e no lycée. Considerar os alunos como sujeitos é responsabilizá-los e é um meio de motivá-los à leitura.

Como fazer emergir as leituras singulares e tornar vivas as experiências de leitura quando eles aprenderam a suprimir ou ocultar seu envolvimento subjetivo? Como suscitar uma leitura envolvente e sobretudo como implementar um acompanhamento didático de envolvimento do sujeito com a obra? Diversas abordagens são possíveis.

a) Como suscitar o envolvimento dos alunos-leitores? que suportes utilizar para coletar e analisar as experiências de leitura?

\section{Modificar os questionamentos sobre os textos}

- questionamento direto das imaginações individuais: perguntar aos alunos quais imagens eles associam aos lugares evocados por uma obra, como eles imaginam o personagem, como eles imaginam os acontecimentos...

- deslocamento do questionamento sobre os personagens sugerido por M-J. Fourtanier e G. Langlade ${ }^{11}$ : no lugar de “quem é o personagem principal?” ou “qual é a função do personagem no esquema actancial?", interrogamos os alunos sobre os personagens que lhes tocaram, que eles gostaram, quem eles detestaram, sobre o julgamento moral que eles fazem sobre as ações, sobre as atitudes que eles teriam se eles estivessem em seu lugar...

\section{O diário de leitura (ou caderno de leitura)}

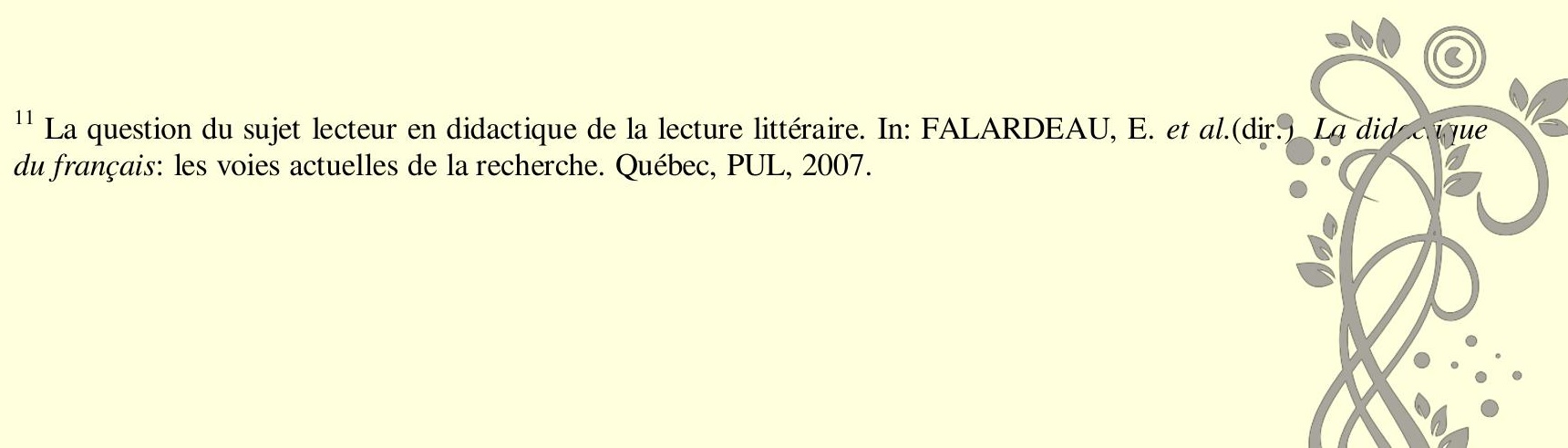


- recorrer ao diário de leitura ou caderno de leitura, acompanhado ou não de instruções, para guardar traços das reações do leitor: concebido como preparação para a leitura

${ }^{11}$ La question du sujet lecteur en didactique de la lecture littéraire. In: FALARDEAU, E. et al.(dir.) La didactique du français: les voies actuelles de la recherche. Québec, PUL, 2007. 
analítica, o diário de leitura permite não apenas um envolvimento dos alunos na leitura, mas também um trabalho sobre a articulação e a passagem entre as posturas de leitura.

\section{A escrita de invenção}

- completar uma obra: escrever nos brancos do texto, imaginar uma sequência... enfim, utilizar todos os recursos da escrita de invenção para fazer aparecer particularmente a "atividade ficcionalizante" do sujeito leitor.

- levantar questões que levem à expressão das impressões de leitura, à reação às ideias do texto, favorecendo uma apropriação pessoal; propor exercícios de escrita que permitam aos alunos envolver-se afetivamente e eticamente com sua leitura.

\section{A leitura em voz alta}

- a leitura em voz alta como interpretação subjetiva dos textos: para defender essa abordagem eu me apoiarei no trabalho de antropologia da leitura de Michèle Petit, que alimentou as reflexões dos especialistas em didática, com seu primeiro livro Eloge de la lecture. La construction de soi (2002), e com o mais recente, L'art de lire ou comment résister à l'adversité? (2008), em que ela relata interessantes experiências literárias realizadas em países da América do Sul confrontados por conflitos armados, crises econômicas ou catástrofes naturais e estuda dispositivos inéditos de leitura. É impossível relatar aqui a riqueza desse trabalho. Eu me deterei apenas à passagem em que ela relembra que o gosto pela leitura deve muito à voz alta (na França, entre os grandes leitores, o peso do fato de terem se beneficiado de histórias contadas pelos pais todos os dias é duas vezes maior em relação aos que nunca ouviram uma história), e que trata-se também de ler para "encontrar um mundo de sensações e ritmos" (p. 46). Ela escreve:

[...] na França, mais que em outros países, talvez, a quebra entre o mundo da inteligência, da razão e o da sensibilidade foi altamente consumada. A escola, há muito tempo, estuda a literatura como qualquer coisa de exterior a si, que não é vivida, provada, sentida. Algumas abordagens são 
utilizadas até mesmo para maximizar a distância com o corpo, para repudiar toda a emoção, vista como um exagero perigoso. E o corpo, enquanto isso, foi esquecido, impensado pelas pesquisas sobre a leitura,

${ }^{12}$ L'art de liter ou comment résister à l'adversité ? Berlin, 2008, p. 48.

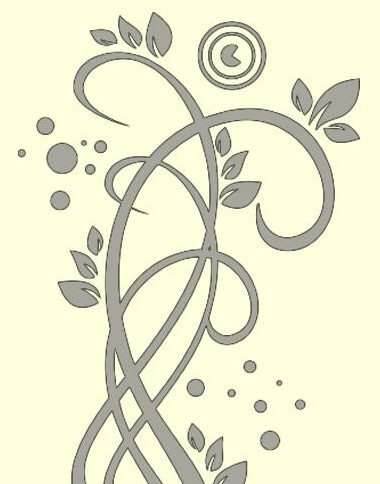


reduzido a uma atividade mental, em vez de uma atividades física que trabalha, engajando de maneira indissolúvel o corpo e a mente."12

A leitura em voz alta é portanto um meio de fazer ouvir ao mesmo tempo a voz do texto e a do leitor que lhe dá sua sensibilidade própria, uma proposição de interpretação em que se pode simplesmente saborear o prazer sensorial dos sons e do ritmo. A dificuldade é certamente a da leitura ela mesma, porque é difícil passar uma interpretação, uma intenção na leitura. Porém, é também uma maneira de combater a ideia de que deve haver "o" tom em benefício daquela que diz haver várias interpretações possíveis da partitura que é o texto, que podem ser anotadas, comparadas com outras leituras, dar espaço a discussões sobre as escolhas feitas, preparar-se em grupos...

- Outras questões "sensíveis" das obras literárias podem ser experimentadas como a leitura musical que, solicitando aos alunos a associação de uma obra musical com sua leitura, representa uma outra forma de apropriação subjetiva.

\section{A ilustração ou a utilização de imagens}

- última proposição: ilustração ou utilização de imagens nos diários ou cadernos de leitura ou na realização de antologias, é um meio de driblar a dificuldade de escrita e de exprimir uma leitura subjetiva.

- Exemplo do dispositivo experimentado por um estagiário PLC2 no collège para a leitura de poesias:

Ele pediu aos seus alunos que falassem em seu diário de leitura, sobre um poema por dia (o que constituía doze poemas em duas semanas). Cada aluno deveria escolher, em cada dia da semana, como quisesse, um poema.

Esse diário estruturava-se por algumas questões:

- O título do poema escolhido.

- "Qual é o assunto do poema? quais são os principais temas?"

- "Qual é a minha opinião sobre o poema?" 
Revista Letras Raras ISSN: 2317-2347 - Vol. 4, No 1 - 2014

- "Quais são as minha ideias para apresentar esse poema (desenho/colagem/ découpage etc...)"

${ }^{12}$ L'art de liter ou comment résister à l'adversité ? Berlin, 2008, p. 48.

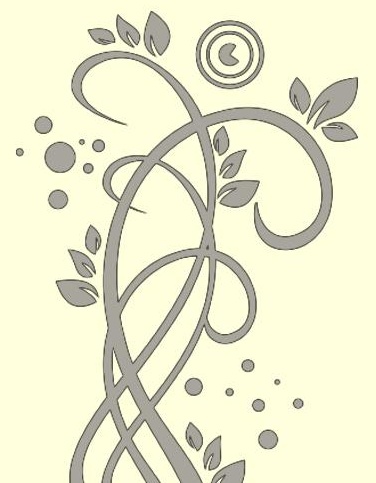


A seguir, os alunos são convidados a apresentar um poema para a classe, explicando o porquê de sua escolha para depois, em um outro momento, haver a troca dos diários de leitura com outro aluno.

A produção final é uma antologia pessoal realizada a partir de uma escolha de poemas dentre os estudados com uma ilustração ou imagem criada para os poemas escolhidos.

Esses diferentes dispositivos de leitura permitem fazer advir os "textos dos leitores" que se constituem no entremeio incerto que liga leitores e obras, além de fazer emergir as identidades de leitor dos alunos.

\section{b) Fazer emergir as "posturas de leitura" dos alunos: uma experiência conduzida por Dominique Bucheton 13}

As posturas de leitor são definidas por D. Bucheton como "os modos de ler integrados, tornados não conscientes, construídos na história da leitura de cada sujeito, convocados em função da tarefa de leitura, do contexto e seus desafios, assim como das especificidades do texto."

A experiência, conduzida com três classes em último ano do collège, consistiu em fazer os alunos lerem uma novela de D. Daenninckx, La Tire-lire, e após fazer um comentário livre de uma página. A análise dos textos escritos permitiram a D. Bucheton evidenciar cinco posturas de leitura nos alunos.

- Postura 1. O texto desafio. A leitura fracassada: o texto do aluno tem a aparência de uma tarefa escolar, desprovida de significação e perigosa (escrever revela). Formas diversas de recusa ou sabotagem da atividade solicitada (leitura parcial do texto ou muito superficial, com confusões sobre os personagens e ações, descrição técnica sem iniciar a construção de uma significação).

- Postura 2. O texto ação. O leitor se situa no nível dos personagens que ele toma por pessoas. Ele procura compreendê-los, explicar suas motivações, a lógica de suas ações. 
Para compreender os atos dos personagens ele aciona seu próprio sistema de valores morais. Essa atitude leva às vezes à expressão de sua emoção em relação aos

c) As consequências das escolhas das obras e das posturas do professor:

${ }^{13}$ Les postures de lecture des éleves au collège. In : MASSOL, J-L. ; DEMOUGIN, P. Lecture póre, tectare scolaire. La question de la littérature à l'école. CRDP, 1999. 
personagens do texto (pena, simpatia, rejeição), pelas pessoas reais que esses personagens simbolizam ou evocam ("Isso deve ser difícil"), e por eles mesmos uma vez que eles atualizam, pela leitura, seus medos e fantasias (ele lê uma narrativa como um espelho do que ele vive ou pode viver). Porém o aluno não confunde de todo o narrado com a realidade: ele simplesmente entra no jogo da ficção, jogo que pode ir até o julgamento dos personagens.

- Postura 3. O texto signo. O texto proposto é lido como uma fábula, o leitor toma o texto como uma metáfora da mensagem do autor, que resta ser decifrada por trás da fábula. $\mathrm{O}$ texto lido vem a ser um lugar de encontro não apenas com os personagens, mas com as ideias. Ele pode ser percebido como um "reflexo" de uma realidade sobre a qual o autor quer enviar o nosso olhar (leitura sócio-histórica de caráter referencial). O texto pode ser percebido como a metáfora de uma questão, de valores postos em evidência: o leitor questiona e analisa os temas, os valores do texto, o escopo simbólico dos gestos dos personagens.

- Postura 4. O texto trampolim. O aluno utiliza o texto para se deixar levar pelas reflexões pessoais. O comentário decola a partir das realidades lidas no texto. Ele é a expressão do ponto de vista próprio do leitor. Para alguns leitores, tem-se o sentimento de que o ponto de vista enunciado preexiste ao comentário e de que o texto lido é apenas um pretexto.

- Postura 5. O texto objeto. O leitor se coloca fora do texto e analisa o texto, suas formas, seus efeitos, a maneira com que o texto faz para construir uma significação ou seduzir o leitor.

Dentre os alunos que participaram da pesquisa, muito poucos praticam esse modo de leitura.

O interessante dessa experiência é aprender a identificar nos alunos as posturas de leitor 
em diferentes textos escritos. Podemos então partir dessas posturas para analisar e construir dispositivos didáticos para fazê-los evoluir. Entretanto, esse tipo de experiência pressupõe o apoio em textos que permitam o investimento subjetivo dos alunos.

c) As consequências das escolhas das obras e das posturas do professor:

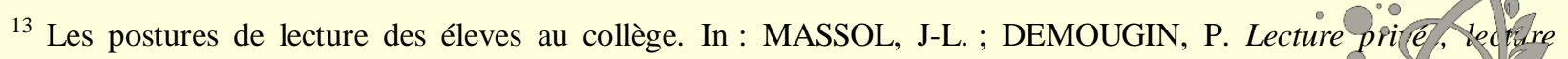
scolaire. La question de la littérature à l'école. CRDP, 1999. 
Uma vez que o acolhimento aos afetos dos alunos seja algo bem-vindo, assim como favorecer as descobertas de questões pessoais de leitura e não evitar o conteúdo existencial e ideológico das obras, não se deve esquivar da dimensão ética e antropológica da literatura, pois é nessa dimensão que a leitura torna-se uma experiência humana com fortes apelos simbólicos. Isto supõe, como nos lembram G. Langlade e M.-J.Fourtanier, "enriquecer o corpus com obras aptas a suscitar mais reações pessoais dos alunos e a provocar a realização de leituras plurais, isto é, de obras que enfoquem menos o jogo sobre os códigos literários e mais as questões humanas (éticas, relativas à fantasia, estéticas...), que constituem a base profunda da produção $\operatorname{artística"~} 14$.

Isso exige do professor um forte envolvimento de sua própria leitura com os textos escolhidos - como ensinar algo que, no domínio da literatura, não nos faz vibrar e não nos leva a pensar? - textos que, por outro lado, lhe permitam propor aos alunos situações de leitura suscetíveis de provocar choques estéticos e emoções de toda ordem. A explicação literária deve também apoiar-se numa verdadeira experiência de leitura do professor.

Ora, parece que hoje a abordagem formalista dos textos seja por vezes um meio de fuga ou de esquiva da leitura como experiência autêntica do sujeito dentro de um debate de ideias.

Isso é o que demonstrou um estudo conduzido a partir de uma centena de descrições orais para a l'EAF ${ }^{15}$ em 2009. Aqui está a conclusão:

No final desse percurso, é claro que a literatura de ideias não tem mais o direito de cidadania no ensino do francês na forma como agem os professores, conforme pudemos perceber por meio das descrições e com base nos livros didáticos que lhes são propostos. A principal razão desse abandono reside provavelmente na ênfase colocada sobre a ação argumentativa em função do objeto e da perspectiva de estudo. Ora, eles tendem a fazer da literatura de ideias um banco de abordagens argumentativas.

Geralmente, parece que o ensaio e as formas não ficcionais são desprezadas em detrimento dos "apólogos" e em particular dos contos voltairianos. Similarmente, os gêneros argumentativos diretos como o discurso são pouco representados. Esses fenômenos se desenham mais

16 G. Plist, A. Vibert, "Latitterature d'idées appartient-elle à la culture commune ? », colóquio « Manières de critiquer, manières d'enseigner la litterature », Arras, novembre 2009, no prelo.

${ }^{17}$ Op. cit., p. 117. 
claramente ainda nas descrições do que nos livros didáticos. Tudo se passa como se o ensino privilegiasse os textos em que a literariedade seja mais óbvia, ainda que a literatura tenha desobrigado hoje, de certa forma,

${ }^{14}$ Op. cit., p. 119.

${ }^{15}$ Exame nacional aplicado aos alunos franceses. (N.T.).

16 G. Plisom, A. Vibert, "La litterature d'idées appartient-elle à la culture commune ? », colóquio « Manières de critiquer, manières d'enseigner la litterature », Arras, novembre 2009, no prelo.

${ }^{17}$ Op. cit., p. 117. 
a literariedade condicional por dicção, como descreve Gérard Genette em Fiction et diction. Assim se explica que a questão de escrita do ensaio seja ausente nas sínteses ou questões dos livros didáticos, ou ainda o fato de não propormos aos alunos um primeiro confronto com textos de ideias não literárias.

Três constatações se impõem claramente, e que são também problemas: o lugar de destaque dentro das instituições escolares de uma forte imagem pouco problemática das Luzes - e, se nos permitimos relembrar, acadêmica; uma flutuação teórica nas noções de argumentação pelos livros didáticos, à qual anexa-se toda uma parte de não dito: por que tais debates, autores, gêneros e não outros? sobretudo, qual posicionamento propor aos leitores adolescentes para fazê-los refletir sobre o que fundamenta tal literatura e não somente sobre as formas de argumentação ${ }^{16}$

\section{Conjugar leitura subjetiva e comunidade interpretativa}

Trata-se então de lançar um olhar positivo sobre aquilo que parece ser a marca de um envolvimento pessoal: a identificação e ilusão referencial pertencem à experiência literária e são muito preferíveis à postura de exterioridade. Não se deve evitar o convite aos alunos a exprimir seus prazeres e desprazeres de leitura. Modificamos a relação com o texto construído na leitura escolar desenvolvendo uma "didática de envolvimento" do sujeito leitor com a obra. Evitar a censura aos traços nos discursos dos alunos de um envolvimento pessoal, imaginativo e fantástico ou moral não é renunciar ao estudo da obra em sua dimensão formal e objetivável, nem renunciar à avaliação das condutas interpretativas.

A subjetividade do leitor pode exceder às injunções do texto e surgir de maneira imprevisível onde ela não é esperada. Até que ponto o sujeito leitor pode matamorfosear o texto? quais são os limites dados a essa reconfiguração? e como construir a postura do leitor expert a partir de diversas leituras subjetivas se, como escrevem G. Langlade e M.-J. Fourtanier, "o envolvimento subjetivo do leitor é o primeiro modo de acesso às obras"? ${ }^{17}$ Uma primeira resposta consiste em se fundamentar nos "limites da interpretação", como são definidos por

16 G. Plist, A. Vibert, "La titterature d'idées appartient-elle à la culture commune ? », colóquio « Mánières de critiquer, manières d'enseigner la litterature », Arras, novembre 2009, no prelo.

${ }^{17}$ Op. cit., p. 117. 
Umberto Eco, entre a inacessível intenção do autor e a discutível intenção do leitor, há a intenção do texto. Esta é também sua própria proteção para todo o leitor sensato, de boafé, e que tem um

16 G. Plisom, A. Vibert, "La litterature d'idées appartient-elle à la culture commune ? », colóquio « Manières de critiquer, manières d'enseigner la litterature », Arras, novembre 2009, no prelo.

${ }^{17}$ Op. cit., p. 117. 
mínimo conhecimento enciclopédico requerido: a intenção do texto é o mínimo consenso que permite fixar as bases interpretativas e recusar as interpretações inaceitáveis.

Mas, podemos também, segundo uma perspectiva pragmática oposta à de Eco nos fundamentar na noção de "comunidade interpretativa", que devemos a Stanley Fish: para ele, os gestos interpretativos, as normas aceitáveis e inaceitáveis são concebíveis somente no seio de comunidades interpretativas que dão às subjetividades individuais suas formas, seus limites, suas ideias. Com essa noção, a oposição entre subjetividade e objetividade não tem mais lugar de ser. Para Fish, as significações "são ao mesmo tempo subjetivas e objetivas: elas são subjetivas porque são inerentes ao ponto de vista particular, portanto são não universais; elas são objetivas porque o ponto de vista que lhes liberta é público e convencional em vez de individual ou singular. Assim, os alunos de Fish puderam analisar como poema palavras propostas de propósito no quadro (que eram de fato nomes de linguistas indicados aos estudantes no curso anterior) porque, enquanto membros de uma comunidade literária trabalhando sobre a poesia religiosa, eles já sabiam o que era um poema e estavam impedidos de pensar que os nomes dispostos no quadro como poema não eram necessariamente um poema religioso. As consciências dos leitores são constituídas por "um conjunto de noções convencionais que, quando ativadas, constituem por sua vez um objeto convencional, e visto convencionalmente."18 Compreendemos no interior dos pressupostos de um contexto. Ninguém pode dizer que seus atos interpretativos são absolutamente próprios, mas eles emergem em virtude da posição em um meio social organizado onde são sempre compartilhados.

Quais são as conclusões a respeito da explicação literária em sala de aula? Ao contrário dos alunos de Stanley Fish que formam já uma comunidade literária, a dos nossos alunos está, em grande parte, ainda em construção, mesmo que os leitores estejam de fato já bastante condicionados pela comunidade interpretativa que constitui a sociedade onde vivem.

A sala de aula deve portanto ser pensada como um lugar de emergência e de confrontação de leituras subjetivas. 
Quais dispositivos didáticos para que a sala de aula venha a ser uma verdadeira "comunidade interpretativa"?

${ }^{18}$ FISH, Stanley. Quand lire c'est faire. L'autorité des communautés interprétatives. Paris : Les prairies ordinaires, 2007. 
- O confronto dos diários de bordo: diários de bordo mantidos a dois ou trocados, diários de bordo para a preparação de "círculos de leitura";

- A prática dos círculos de leitura: a discussão do círculo de leitura apoiada nos diários de bordo de alunos voluntários precederá e preparará a leitura analítica do texto.

- A prática do debate interpretativo: essa prática, introduzida pelos acompanhamentos do programa da escola primária em 2002, ganharia se fosse estendida para escola secundária até o lycée. O debate poderia se fixar nos pontos de incerteza do texto, aqueles que colocam o leitor modelo em dificuldade ou o questiona, mas também nos valores do texto e na relação dos alunos-leitores com seus valores.

\section{Conclusão}

A leitura literária alimenta-se da pluralidade das experiências e se constrói na intersubjetividade. Sem exigir o abandono total das intuiçõos singulares, trata-se de alcançar a constituição de uma comunidade literária onde seja possível compartilhar leituras e confrontar interpretações. Essa partilha deve fazer-se num retorno permanente ao texto a fim de enriquecer as leituras singulares e evidenciar o que pode ser comum a todos.

VIBERT, Anne. Expliquer un texte littéraire: ce que la recherche en didactique de la littérature peut apporter au renouvellement et à la diversification des pratiques. 2012. Disponível em:

< http://www.ac-aix-marseille.fr/pedagogie/upload/docs/application/pdf/2012-

09/didactique_de_la_litterature_et_sujet_lecteur.pdf>. Acesso em 10 mar. 2014.

Recebido em 07 de julho de 2014 Aceito para publicação em 17 de agosto de 2014

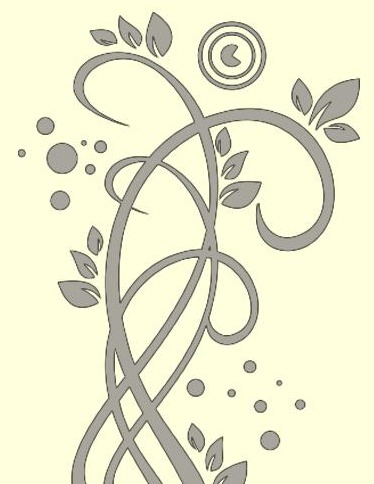

